\title{
PRN Medicines Management for Older People with Long-Term Mental Health Disorders in Home Care
}

\author{
Mojtaba Vaismoradi (1D) \\ Shazia Jamshed ${ }^{2}$ \\ Stefan Lorenzl ${ }^{3,4}$ \\ Piret Paal $\mathbb{D}^{5}$
}

'Faculty of Nursing and Health Sciences, Nord University, Bodø, 8049, Norway;

${ }^{2}$ Clinical Pharmacy and Practice, Faculty of Pharmacy, University Sultan Zainal Abidin, Terengganu, 22200, Malaysia;

${ }^{3}$ Professorship for Palliative Care, Institute of Nursing Science and -Practice, Paracelsus Medical University, Salzburg, 5020, Austria; ${ }^{4}$ Department of Neurology, Klinikum Agatharied, Hausham, 83734, Germany; ${ }^{5} \mathrm{WHO}$ Collaborating Centre at the Institute for Nursing Science and Practice, Paracelsus Medical University, Salzburg, A-5020, Austria
Correspondence: Mojtaba Vaismoradi Faculty of Nursing and Health Sciences, Nord University, Bodø, 8049, Norway Tel +47 755178 I3

Email mojtaba.vaismoradi@nord.no

\begin{abstract}
Older people with long-term mental health conditions who receive care in their own home are vulnerable to the inappropriate use of medications and polypharmacy given their underlying health conditions and comorbidities. Inappropriate use of pro re nata (PRN) medications in these older people can enhance their suffering and have negative consequences for their quality of life and well-being, leading to readmission to healthcare settings and the increased cost of health care. This narrative review on published international literature aims at improving our understanding of medicines management in home care and how to improve PRN medication use among older people with long-term health conditions in their own home. Accordingly, the improvement of PRN medicines management for these older people requires the development of an individualised care plan considering 'reduction of older people's dependence on PRN medications', 'empowerment of family caregivers', and 'support by healthcare professionals.' PRN medication use should be reduced through deprescription and discontinuation strategies. Also, older people and their family caregivers should be encouraged to prioritize the use of non-pharmacologic methods to relieve physical and psychological problems. Besides the empowerment of family caregivers through role development, education and training about PRN medications, and involvement in decision-making, they need support by the multidisciplinary network in terms of supervision, monitoring, and home visits.
\end{abstract}

Keywords: family caregiver, home care, medication, medicines management, mental health, older people, patient safety, pro re nata, PRN

\section{Introduction}

Long-term mental health conditions consist of various disorders characterised by abnormal thoughts, cognition, perceptions, emotions, behaviours, and relationships with others that cause long-term suffering and disability. ${ }^{1}$ It has been reported that the risk of developing long-term mental health disorders especially cognitive disorders and depression among older people, as aged above 60 years, is higher than other age groups; for instance, $15 \%$ of older adults suffer from a mental disorder. ${ }^{2}$ Also, about $50 \%, 10 \%$, and $17 \%$ of older people suffer from cognitive disorders, anxiety, and depression, respectively.,

The appropriate use of medications consisting of antidepressants, anti-anxiety, stimulants, antipsychotics, and mood-stabilisers have been recognised to have a crucial role in the treatment of long-term mental health disorders. ${ }^{5,6}$ About $70 \%$ of older people are prescribed at least one psychotropic medication, but the 
increased prescription of psychotropic medications and benzodiazepines has been associated with a reduced quality of life. ${ }^{7}$

Opioids, anticoagulants, and antipsychotics are high-risk medications in the medication regimen of these older people despite their benefits. ${ }^{8}$ The total exposure of older people to medications including anticholinergic and sedatives is associated with a higher risk of hospital stays. ${ }^{9}$ The prevalence of potentially inappropriate medications for older people with long-term mental health conditions with the presence of polypharmacy ranges from $53.2 \%$ to $89.8 \%{ }^{10}$

The prevention of mortality and morbidities among older people with long-term mental health conditions requires the reduction of complexity of the medication regimen as well as the improvement of medicines management in terms of the reduction of prescribed and nonprescribed medication use and avoiding polypharmacy. ${ }^{11,12}$ This narrative review on published international literature aims at improving our understanding of medicines management in home care and how to improve PRN medication use among older people with long-term health conditions in their own home.

\section{Concerns Over Medicines Management in Home Care}

Medicines management in home care also is accompanied with many concerns affecting the safety of the medication process and quality of life in older people with chronic and long-term mental health conditions and their family caregivers.

Increasing the total number of medications in these older adults has enhanced the risk of potentially inappropriate medications between 2 and 10 times. $^{13}$ Polypharmacy (5-9 medications) and excessive polypharmacy ( $\geq 10$ drugs) have been observed in $39 \%$ and $23 \%$ of older people receiving home care, respectively. ${ }^{14}$ The use of psychotropic medications including antidepressants and other anxiolytic/sedative-hypnotics and benzodiazepines by older people in community and primary healthcare has increased, which has created concerns about appropriate medication use. ${ }^{15,16}$

The home medication review for about $80 \%$ of older people in home care indicates discrepancies with the electronic medical records. ${ }^{17}$ The overall prevalence of potentially inappropriate prescribing in older people in home care has been reported to be $10-38 \%,{ }^{18-20}$ which has been associated with polypharmacy $(\mathrm{OR}=5.4) .{ }^{18,19}$
Complexity of medication regimen $(\mathrm{OR}=1.22)$ and number of medications $(\mathrm{OR}=1.07)$ in older people living in own home are associated with unplanned readmissions and hospitalizations. ${ }^{21,22} \mathrm{~A}$ nation-wide research in Sweden showed that the use of psychotropics and antiepileptic medications was associated with institutionalization. ${ }^{23}$ Also, polypharmacy $(\mathrm{OR}=2.30)$ and excessive polypharmacy $(\mathrm{OR}=4.97)$ have been shown to be associated with frailty among older adults. ${ }^{24}$ Therefore, the medication regimen, adverse drug reactions, and side effects of prescription and non-prescription medications in home care should be carefully assessed given the susceptibility and frailty of older adults with chronic health conditions including mental health disorders living in their own home. ${ }^{25}$

\section{PRN Medicines Management in Home Care}

Pro re nata (PRN) medications management is the administration of prescribed medications based on patients' needs instead of administration in predetermined times. ${ }^{26,27}$ It is commonly used for various types of medications to relieve patients' physical and psychological suffering. Besides acetaminophen and opioids for pain relief, ${ }^{28}$ psychotropic and psycholeptic medications are more commonly prescribed and administered as PRN to older patients with long-term mental health conditions, ${ }^{29-32}$ but the clinical effectiveness of this style of medication use in comparison with other prescription and administration styles of medication has remained unexplored and needs further research. ${ }^{33}$

Inappropriate use of PRN medications can extend the duration of hospitalisation in long-term healthcare settings and hinder the smooth transition of care for older people with chronic health conditions to their own home. Older people with five and more PRN prescriptions have the length of stay $4.8 \pm 4.3$ years in the nursing home. ${ }^{32,34}$ PRN medicines management for psychotropic medications' use by older people with long-term health conditions in their own home has remained underreported. ${ }^{35,36}$ However, issues with the use of prescribed and PRN psychotropic medications among this vulnerable group of patients have been reported including the reason for administration (55-81\%), response to medications (47-92\%), and the possibility of use of nonpharmacologic interventions instead of medications $(64-69 \%) .{ }^{37}$ It has been stated that older adults in the age range of 60-80 years take an average of 10 different prescription and non-prescription medications including PRN. ${ }^{38}$ 
PRN analgesics are commonly used (50\%) by older people living in their own homes. ${ }^{25}$ Polypharmacy with five or more long-term drugs $(\mathrm{OR}=2.1)$ is associated with a higher number of PRN medication use. ${ }^{34}$ Moreover, the highest cost of medication is attributed to psychotropic and neuroleptic medications. ${ }^{39}$ Therefore, improvement of the quality, safety, and cost-effectiveness of medication therapy should be the centre of attention by healthcare professionals who are involved in serving older people with long-term mental health conditions in home care.

\section{Initiatives to Safeguard PRN Medicines Management in Home \\ Care}

Older people with long-term mental health conditions living in their own home need assistance in the management of medications. ${ }^{40}$ They need individualised and goal-oriented care aligned to their needs with the concentration on the identification and reduction of the risk of harm. ${ }^{41}$
Individualised care planning through the appropriate prescription of medications, rectification of negative attitudes and barriers to medicines management including changes in lifestyle patterns, and assistance with the medication process can improve their adherence to the medication's regimen as well as improve care outcomes. ${ }^{42-44}$ In this respect, the improvement of PRN medicines management in home care for older people with long-term mental health conditions requires developing an individualised care plan considering "reduction of older people's dependence on PRN medications", "empowerment of family caregivers in care", and "support by healthcare professionals." (Figure 1).

\section{Reduction of Older People's Dependence on PRN Medications}

Older people with long-term mental health conditions need discontinuation and deprescribing programmes for the chronic and sometimes unnecessary use of medications with the consideration of the possibility of relapse and

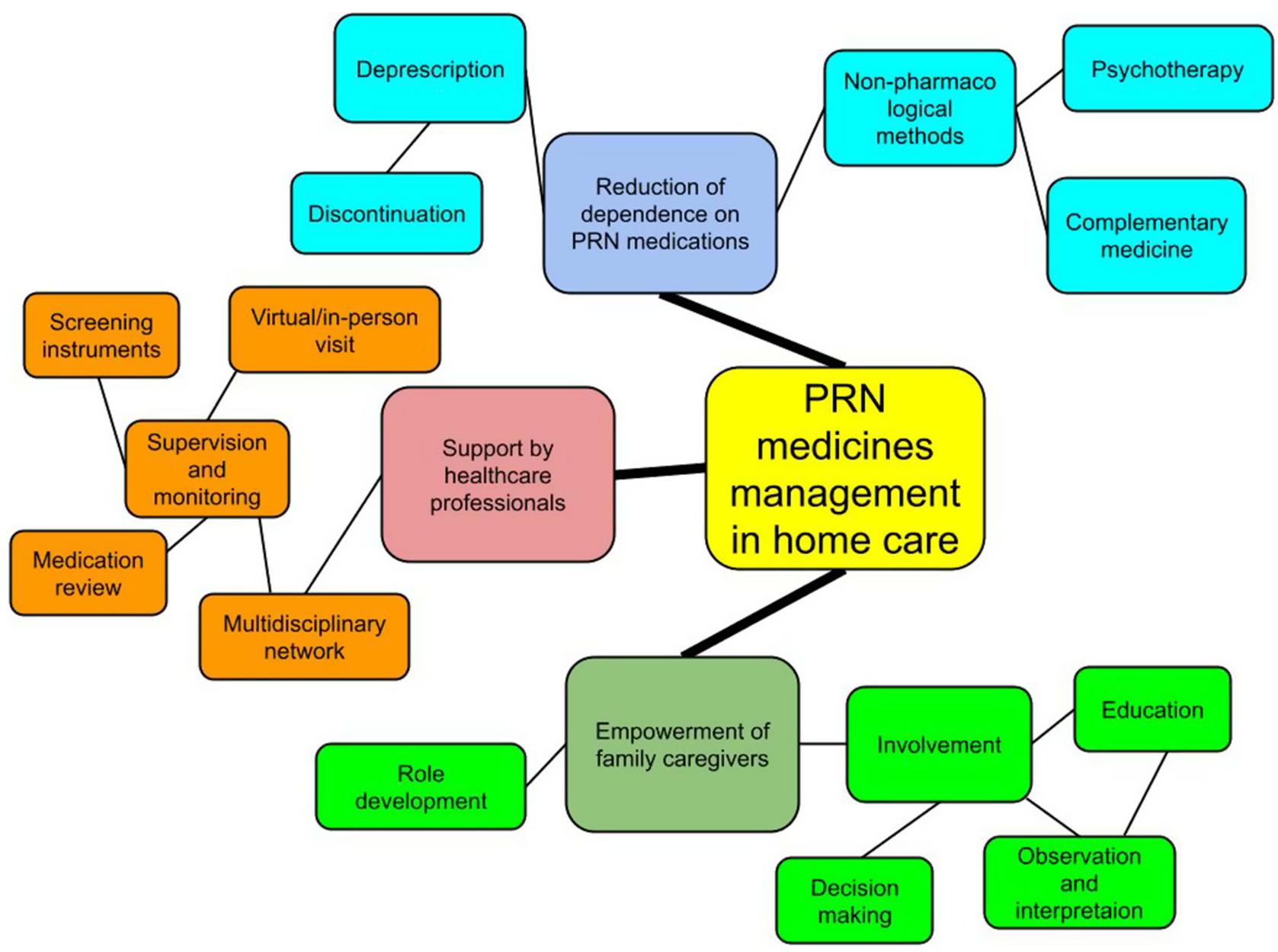

Figure I Improvement of PRN medicines management in home care. PRN stands for pro re nata. 
probable negative consequences on their well-being and quality of life. ${ }^{38,45}$

Deprescribing as the process of tapering or stopping medications to tackle the problem of polypharmacy in older adults consists of the following five steps:

- Medication review and ascertaining reasons for taking each medication;

- Calculation of the risk of medication-related harm and possibility of deprescribing;

- Assessment of the potential benefits and harm of deprescribing for each medication;

- Prioritizing medications with the lowest benefit-harm ratio and adverse withdrawal reactions;

- Implementation of the discontinuation program and monitoring its positive and negative effects. ${ }^{46,47}$

This process should be individualised based on cognitive and functional abilities and comorbidities of each older adult along with the application of close monitoring, ${ }^{48,49}$ given that some older people are open to deprescribing and prefer to play an active role in related decision making, but some others may defer it to their healthcare provider because of lack of knowledge. ${ }^{50}$ Moreover, the success of this program depends on the determination of achievable goals and appropriate time planning as well as the creation of psychological preparation in older people.

Stepwise deprescribing interventions for benzodiazepines through pharmacological substitution, psychological support, cognitive-behavioural therapy, education, shared decision making by the pharmacist, physician and older people have been shown to be effective in dose reduction and discontinuation between $27 \%$ and $80 \%$ of cases. $^{48,51,52}$ Also, discontinuation of neuroleptic medications has been shown to have no detrimental effect on functional and cognitive status of older people with long-term mental health conditions. ${ }^{53}$

Reduction of antipsychotic medications' use by the older people and prevention of its negative consequences on their health and well-being requires the facilitation of access to non-pharmacological methods including psychotherapy, social interventions, cognitive behavioural therapy, and psychoeducation. ${ }^{54-56}$ The effectiveness of psychological and cognitive treatments in reducing the symptoms and suffering of older people with long-term mental health conditions have been shown. ${ }^{57-59}$ Also, they have been shown to have better effects on relieving the symptoms of these older people than pharmacotherapy. ${ }^{60}$
Nonpharmacological and psychosocial interventions such as improving the home environment condition by family caregivers have been shown to reduce the frequency and severity of behavioural and psychological symptoms in older adults with an effect size equal to pharmacotherapy. ${ }^{61}$

In addition, alternative and complementary medicine including aromatherapy, massage, meditation, and music therapy with the consideration of their acceptability by the older people and their family caregivers as well as after balancing their benefits and harm can be used to improve the toleration of discontinued psychotropic medications and reduce the need to medication therapy. ${ }^{62-64}$

\section{Empowerment of Family Caregivers}

Home care initiatives should concentrate on the encouragement of older people to remain independent as much as possible. ${ }^{65}$ However, the progression of cognitive and mental health issues negatively influences the older people's ability to follow up medicines management's interventions in terms of planning, organising, and implementing tasks, which enhances the risk of harm and non-adherence to medications and consequently readmission to the hospital and dependence on family caregivers. ${ }^{66}$ Provision of home care to older people who have chronic and advanced illnesses greatly impacts on the realm of the family caregiver who are often a spouse or child. Although family caregivers' involvement in the medication process can improve medication safety for older people with mental health issues, ${ }^{67}$ it imposes a significant amount of stress and burden of care on them. ${ }^{68-71}$ Family caregivers even suffer from mental illness and care burden may even induce depression among them. $^{72}$

Lack of monitoring device in home care and inability to assess warning signs in older people are barriers to safe medicines management by family caregivers. $^{73}$ Medication management skills by family caregivers as the appropriate identification of symptoms in older people and the administration of PRN medications accordingly are required to enhance the appropriate use of medications and prevent over and under medication use. ${ }^{74}$ Family caregivers should be empowered to be involved in shared decision making that helps with developing an individualized programme for the appropriate prescription of medications with the consideration of older people's medical needs, functional abilities, and well-being. ${ }^{75}$ In this respect, training and education of family caregivers for 
the management of symptoms and behaviours, what potentially can trigger psychological issues in older people with long-term mental health conditions, and medication therapy based on the older people's needs supports appropriate medication use in home care. ${ }^{76-78}$ Family caregivers need to build therapeutic relationships with healthcare professionals to negotiate care, play an active role in care, and be able to manage their role expectations in home care. ${ }^{79}$

\section{Support by Healthcare Professionals}

Older people with long-term mental health conditions and their family caregivers need support and supervision in home care, but they mostly have no access to related services or cannot use them. ${ }^{80}$ An early access to palliative care services is of particular importance with a focus on treatment and provision of support both for older people and their family caregivers. Physical and emotional symptoms of care burden should be regularly assessed to avoid somatic comorbidities, reduce frequent hospital admissions, and ameliorate the low quality of home care. ${ }^{81}$ Support provided by physicians, nurses, pharmacists, and social workers can mediate resilience and burden of care in home care. ${ }^{82}$

Supervision by healthcare professionals encompasses reviewing medication use in home care, rationalizing unnecessary medications and PRN medicines management, and provision of as needed monitoring and referrals. ${ }^{83-85}$ Provision of medication services to older people in home care by healthcare staff including pharmacists can reduce the medication-related hospitalization rate $(36 \%)$ and $\$ 6.6$ million in healthcare cost. ${ }^{86}$

The application of explicit screening instruments for conducting medication reviews aiming at identifying unmet medication needs can significantly improve appropriate medication use. ${ }^{87}$ For instance, STOPP (Screening Tool of Older Persons' Prescriptions) and START (Screening Tool to Alert doctors to Right, ie, appropriate, indicated Treatment) can be used by healthcare professionals to appraise the appropriateness of medication prescriptions for older people in the context of his/her concurrent diagnoses and to be effective in reducing fall incidents, readmission to the healthcare settings, medication omissions, and medication costs. ${ }^{88-91}$ Also, the execution of "NO TEARS" tool: Need and indication; Open questions; Tests and monitoring; Evidence and guidelines; Adverse events; Risk reduction or prevention; Simplification and switches ${ }^{92}$ can provide an efficient medication review in a 10-minute consultation using audio-visual links. It serves as appropriate check

Table I Strategies and Interventions for PRN Medicines Management in Home Care

\begin{tabular}{|l|l|}
\hline Improvement Strategies & Practical Interventions \\
\hline $\begin{array}{l}\text { Reduction of older people's dependence } \\
\text { on PRN medications }\end{array}$ & $\begin{array}{l}\text { Assessment of the older people's and their family caregivers' needs to PRN medications; } \\
\text { Consideration of the impact of discontinuation and deprescription on the older people's physical and } \\
\text { psychological health, and cognitive and functional abilities; Development of an individualised, stepwise } \\
\text { and realistic plan for medication discontinuation and deprescription; Encouragement of the older } \\
\text { people and their family caregivers to use non-pharmacologic, and complementary and alternative } \\
\text { medicine methods }\end{array}$ \\
\hline Empowerment of family caregivers in care & $\begin{array}{l}\text { Consideration of the stress and burden of care on family caregivers; Education and training about } \\
\text { medicines management skills and symptoms indicating the appropriate use of medications; Role } \\
\text { expansion and involvement of family caregivers in decision making initiatives regarding medications; } \\
\text { Building close therapeutic relationships between family caregivers and healthcare professionals; }\end{array}$ \\
\hline Support by healthcare professionals & $\begin{array}{l}\text { Facilitation of access to palliative and supportive home care; Continuous assessment of the symptoms } \\
\text { of care burden; Development of the multidisciplinary network of home care consisting of physicians, } \\
\text { nurses, pharmacists, and social workers; Frequent medication review and the rationalisation of } \\
\text { medication use; Application of screening instruments for identifying needs to medications; Virtual and } \\
\text { in-person home visits for monitoring the use of medications; Provision of education, consultation, } \\
\text { decision support, problem-solving, and clinical care; Data collection and sharing between healthcare } \\
\text { professionals in various healthcare settings during transition of care }\end{array}$ \\
\hline
\end{tabular}

Notes: A guideline is needed to help with the selection of best medication for PRN use, its dosage, frequency, and administration method in home care. Also, more original research should be carried out to identify barriers to and the facilitators of appropriate PRN medicines management in home care including relationships between older people and family caregivers, cooperation with healthcare professionals in home care, as well as dependence on medications especially opioids. Additionally, the effectives of interventions aiming at the reduction of related issues and improvement of medication safety in home care should be studied. 
and balance measure for prescribed and PRN medications at home and can minimize caregiver's fatigue.

Telehealth services including virtual home visits consisting of the use of audio-visual communication devices such as videoconference and videophones in a daily manner and in combination with in-person visits as low-cost and feasible supervision methods can support families with medicines management and improve appropriate medication use by the older people in home care. ${ }^{93-95}$ Also, technology has been recognised as an appropriate platform for education, consultation, decision support, problem-solving, social support, monitoring the healthcare condition, and even delivery of clinical care such as assistance with medication dispensing and administration aiming at the enhancement of the quality of medication process by family caregivers. ${ }^{45,96}$

The development of a multidisciplinary care programme through organising a network linking healthcare specialists including community pharmacist, geriatrician, and community nurse that supports family caregivers with pharmacological and psychosocial treatments in home care as well as collect and share information between healthcare professionals to optimize managing the complex medication regimen is one part of monitoring and supervision in home care. ${ }^{97-99}$

\section{Conclusion}

There is a need to pay more attention to the safety of the medication process in home care and explore factors that cause over-prescription of medications and polypharmacy influencing the safety of older people with long-term mental health condition in home care.

Healthcare professionals in the multidisciplinary healthcare team should assess and monitor the use of prescribed, non-prescribed, and PRN medications in home care and develop individualised programmes for PRN medicines optimisation (Table 1).

\section{Abbreviations}

PRN, Pro re nata; OR, odds ratio; STOP: Screening Tool of Older Persons' Prescriptions; START: Screening Tool to Alert doctors to Right, ie, appropriate, indicated Treatment; NO TEARS: Need and indication, Open questions, Tests and monitoring, Evidence and guidelines, Adverse events, Risk reduction or prevention, Simplification and switches.

\section{Acknowledgments}

Article processing charge was paid by Nord University, Bodø, Norway.

\section{Disclosure}

The authors report no conflicts of interest in this work.

\section{References}

1. World Health Organization (WHO). Mental disorders. Available from: https://www.who.int/news-room/fact-sheets/detail/mentaldisorders. Accessed April 16, 2021.

2. World Health Organization (WHO). Mental health of older adults. Available from: https://www.who.int/news-room/fact-sheets/detail/ mental-health-of-older-adults. Accessed April 16, 2021.

3. Patel M, Bhardwaj P, Nebhinani N, Goel AD, Patel K. Prevalence of psychiatric disorders among older adults in Jodhpur and stakeholders perspective on responsive health system. J Family Med Prim Care. 2020;9(2):714-720. doi:10.4103/jfmpc.jfmpc_1016_19

4. Seitz D, Purandare N, Conn D. Prevalence of psychiatric disorders among older adults in long-term care homes: a systematic review. Int Psychogeriatr. 2010;22(7):1025-1039. doi:10.1017/ s1041610210000608

5. World Health Organization (WHO). Pharmacological treatment of mental disorders in primary health care. Available from: https:// apps.who.int/iris/bitstream/handle/10665/44095/9789241547697_ eng.pdf; sequence=1. Accessed April 16, 2021.

6. Center TNIoMHIR. Mental Health Medications. Available from: https://www.nimh.nih.gov/health/topics/mental-health-medications /index.shtml. Accessed April 16, 2021.

7. Harrison SL, Bradley C, Milte R, et al. Psychotropic medications in older people in residential care facilities and associations with quality of life: a cross-sectional study. BMC Geriatr. 2018;18(1):60. doi:10.1186/s12877-018-0752-0

8. Anathhanam S, Powis RA, Cracknell AL, Robson J. Impact of prescribed medications on patient safety in older people. Ther Adv Drug Saf. 2012;3(4):165-174. doi:10.1177/2042098612443848

9. Lönnroos E, Gnjidic D, Hilmer SN, et al. Drug Burden Index and hospitalization among community-dwelling older people. Drugs Aging. 2012;29(5):395-404. doi:10.2165/11631420-000000000-00000

10. Redston MR, Hilmer SN, McLachlan AJ, Clough AJ, Gnjidic D. Prevalence of potentially inappropriate medication use in older inpatients with and without cognitive impairment: a systematic review. J Alzheimers Dis. 2018;61(4):1639-1652. doi:10.3233/jad-170842

11. Bunn F, Dickinson A, Simpson C, et al. Preventing falls among older people with mental health problems: a systematic review. BMC Nurs. 2014;13(1):4. doi:10.1186/1472-6955-13-4

12. Wimmer BC, Bell JS, Fastbom J, Wiese MD, Johnell K. Medication regimen complexity and polypharmacy as factors associated with all-cause mortality in older people: a population-based cohort study. Ann Pharmacother. 2016;50(2):89-95. doi:10.1177/1060028015621071

13. Lau DT, Mercaldo ND, Harris AT, Trittschuh E, Shega J, Weintraub S. Polypharmacy and potentially inappropriate medication use among community-dwelling elders with dementia. Alzheimer Dis Assoc Disord. 2010;24(1):56-63. doi:10.1097/ WAD.0b013e31819d6ec9

14. Giovannini S, van der Roest HG, Carfì A, et al. Polypharmacy in home care in Europe: cross-sectional data from the ibenc study. Drugs Aging. 2018;35(2):145-152. doi:10.1007/s40266-018-0521-y

15. Maust DT, Blow FC, Wiechers IR, Kales HC, Marcus SC. National trends in antidepressant, benzodiazepine, and other sedative-hypnotic treatment of older adults in psychiatric and primary care. $J$ Clin Psychiatry. 2017;78(4):e363-e371. doi:10.4088/JCP.16m10713

16. Moncada LV. Management of falls in older persons: a prescription for prevention. Am Fam Physician. 2011;84(11):1267-1276.

17. Tiihonen M, Nykänen I, Ahonen R, Hartikainen S. Discrepancies between in-home interviews and electronic medical records on regularly used drugs among home care clients. Pharmacoepidemiol Drug Saf. 2016;25(1):100-105. doi:10.1002/pds.3909 
18. Bao Y, Shao H, Bishop TF, Schackman BR, Bruce ML. Inappropriate medication in a national sample of US elderly patients receiving home health care. $J$ Gen Intern Med. 2012;27(3):304-310. doi:10.1007/s11606-011-1905-4

19. Bradley MC, Fahey T, Cahir C, et al. Potentially inappropriate prescribing and cost outcomes for older people: a cross-sectional study using the Northern Ireland Enhanced Prescribing Database. Eur $J$ Clin Pharmacol. 2012;68(10):1425-1433. doi:10.1007/s00228012-1249-y

20. Golden AG, Preston RA, Barnett SD, Llorente M, Hamdan K, Silverman MA. Inappropriate medication prescribing in homebound older adults. J Am Geriatr Soc. 1999;47(8):948-953. doi:10.1111/ j.1532-5415.1999.tb01289.x

21. Wimmer BC, Bell JS, Fastbom J, Wiese MD, Johnell K. Medication regimen complexity and number of medications as factors associated with unplanned hospitalizations in older people: a population-based cohort study. J Gerontol a Biol Sci Med Sci. 2016;71(6):831-837. doi:10.1093/gerona/glv219

22. Wimmer BC, Dent E, Bell JS, et al. Medication regimen complexity and unplanned hospital readmissions in older people. Ann Pharmacother. 2014;48(9):1120-1128. doi:10.1177 1060028014537469

23. Johnell K, Fastbom J. Antiepileptic drug use in community-dwelling and institutionalized elderly: a nationwide study of over 1,300,000 older people. Eur J Clin Pharmacol. 2011;67(10):1069-1075. doi:10.1007/s00228-011-1051-2

24. Saum KU, Schöttker B, Meid AD, et al. Is polypharmacy associated with frailty in older people? Results from the ESTHER cohort study. J Am Geriatr Soc. 2017;65(2):e27-e32. doi:10.1111/jgs.14718

25. Pokela N, Bell JS, Lihavainen K, Sulkava R, Hartikainen S. Analgesic use among community-dwelling people aged 75 years and older: a population-based interview study. Am $J$ Geriatr Pharmacother. 2010;8(3):233-244. doi:10.1016/j. amjopharm.2010.05.001

26. Vaismoradi M, Amaniyan S, Jordan S. Patient safety and Pro Re Nata prescription and administration: a systematic review. Pharmacy. 2018;6(3). doi:10.3390/pharmacy6030095

27. Vaismoradi M, Jordan S, Vizcaya-Moreno F, Friedl I, Glarcher M. PRN medicines optimization and nurse education. Pharmacy. 2020;8 (4). doi:10.3390/pharmacy 8040201

28. Nawai A, Leveille SG, Shmerling RH, van der Leeuw G, Bean JF. Pain severity and pharmacologic pain management among community-living older adults: the MOBILIZE Boston study. Aging Clin Exp Res. 2017;29(6):1139-1147. doi:10.1007/s40520016-0700-9

29. Griffiths AW, Surr CA, Alldred DP, et al. Pro re nata prescribing and administration for neuropsychiatric symptoms and pain in long-term care residents with dementia and memory problems: a cross-sectional study. Int J Clin Pharm. 2019;41(5):1314-1322. doi:10.1007/s11096019-00883-7

30. Picton L, Ilomäki J, Keen CS, et al. Rates of PRN medication administration in Australian residential aged care. $J$ Am Med Dir Assoc. 2021;22(1):117-123.e1. doi:10.1016/j.jamda.2020.04.033

31. Stasinopoulos J, Bell JS, Ryan-Atwood TE, et al. Frequency of and factors related to pro re nata (PRN) medication use in aged care services. Res Social Adm Pharm. 2018;14(10):964-967. doi:10.1016/j.sapharm.2017.11.004

32. Vaismoradi M, Vizcaya Moreno F, Sletvold H, Jordan S. PRN medicines management for psychotropic medicines in long-term care settings: a systematic review. Pharmacy. 2019;7(4). doi:10.3390/ pharmacy 7040157

33. Douglas-Hall P, Whicher EV. 'As required' medication regimens for seriously mentally ill people in hospital. Cochrane Database Syst Rev. 2015;2015(12):Cd003441. doi:10.1002/14651858.CD003441. pub3
34. Dörks M, Schmiemann G, Hoffmann F. Pro re nata (as needed) medication in nursing homes: the longer you stay, the more you get? Eur J Clin Pharmacol. 2016;72(8):995-1001. doi:10.1007/ s00228-016-2059-4

35. Foebel A, Ballokova A, Wellens NIH, et al. A retrospective, longitudinal study of factors associated with new antipsychotic medication use among recently admitted long-term care residents. $B M C$ Geriatr. 2015;15:128. doi:10.1186/s12877-015-0127-8

36. Richardson K, Kenny RA, Peklar J, Bennett K. Agreement between patient interview data on prescription medication use and pharmacy records in those aged older than 50 years varied by therapeutic group and reporting of indicated health conditions. $J$ Clin Epidemiol. 2013;66(11):1308-1316. doi:10.1016/j.jclinepi.2013.02.016

37. Lindsey PL, Buckwalter KC. Administration of PRN medications and use of nonpharmacologic interventions in acute geropsychiatric settings: implications for practice. $J$ Am Psychiatr Nurses Assoc. 2012;18(2):82-90. doi:10.1177/1078390312438768

38. Reeve E, Wiese MD, Hendrix I, Roberts MS, Shakib S. People's attitudes, beliefs, and experiences regarding polypharmacy and willingness to deprescribe. J Am Geriatr Soc. 2013;61(9):1508-1514. doi:10.1111/jgs. 12418

39. Sköldunger A, Fastbom J, Wimo A, Fratiglioni L, Johnell K. The impact of dementia on drug costs in older people: results from the SNAC study. BMC Neurol. 2016;16:28. doi:10.1186/s12883-0160547-x

40. Westerbotn M, Fahlström E, Fastbom J, Agüero-Torres H, Hillerås P. How do older people experience their management of medicines? J Clin Nurs. 2008;17(5a):106-115. doi:10.1111/j.1365-2702.2007.02151.x

41. Caplan GA, Kurrle SE, Cumming A. Appropriate care for older people with cognitive impairment in hospital. Med J Aust. 2016;205 (10):S12-s15. doi:10.5694/mja15.00898

42. Banning M. A review of interventions used to improve adherence to medication in older people. Int J Nurs Stud. 2009;46(11):1505-1515. doi:10.1016/j.ijnurstu.2009.03.011

43. Kauppi K, Hätönen H, Adams CE, Välimäki M. Perceptions of treatment adherence among people with mental health problems and health care professionals. $J$ Adv Nurs. 2015;71(4):777-788. doi: $10.1111 /$ jan. 12567

44. Lee YM, Yu HY, You MA, Son YJ. Impact of health literacy on medication adherence in older people with chronic diseases. Collegian. 2017;24(1):11-18. doi:10.1016/j.colegn.2015.08.003

45. Reeder B, Demiris G, Marek KD. Older adults' satisfaction with a medication dispensing device in home care. Inform Health Soc Care. 2013;38(3):211-222. doi:10.3109/17538157.2012.741084

46. Gould RL, Coulson MC, Patel N, Highton-Williamson E, Howard RJ. Interventions for reducing benzodiazepine use in older people: meta-analysis of randomised controlled trials. $\mathrm{Br}$ J Psychiatry. 2014;204(2):98-107. doi:10.1192/bjp.bp.113.126003

47. Scott IA, Hilmer SN, Reeve E, et al. Reducing inappropriate polypharmacy: the process of deprescribing. JAMA Intern Med. 2015;175 (5):827-834. doi:10.1001/jamainternmed.2015.0324

48. Paquin AM, Zimmerman K, Rudolph JL. Risk versus risk: a review of benzodiazepine reduction in older adults. Expert Opin Drug Saf. 2014;13(7):919-934. doi:10.1517/14740338.2014.925444

49. Renn BN, Asghar-Ali AA, Thielke S, et al. A systematic review of practice guidelines and recommendations for discontinuation of cholinesterase inhibitors in dementia. Am J Geriatr Psychiatry. 2018;26 (2):134-147. doi:10.1016/j.jagp.2017.09.027

50. Weir K, Nickel B, Naganathan V, et al. Decision-making preferences and deprescribing: perspectives of older adults and companions about their medicines. J Gerontol B Psychol Sci Soc Sci. 2018;73(7):e98e107. doi:10.1093/geronb/gbx138

51. Reeve E, Ong M, Wu A, Jansen J, Petrovic M, Gnjidic D. A systematic review of interventions to deprescribe benzodiazepines and other hypnotics among older people. Eur J Clin Pharmacol. 2017;73(8):927-935. doi:10.1007/s00228-017-2257-8 
52. Tannenbaum C, Martin P, Tamblyn R, Benedetti A, Ahmed S. Reduction of inappropriate benzodiazepine prescriptions among older adults through direct patient education: the EMPOWER cluster randomized trial. JAMA Intern Med. 2014;174(6):890-898. doi:10.1001/jamainternmed.2014.949

53. Ballard C, Lana MM, Theodoulou M, et al. A randomised, blinded, placebo-controlled trial in dementia patients continuing or stopping neuroleptics (the DART-AD trial). PLoS Med. 2008;5(4):e76. doi:10.1371/journal.pmed.0050076

54. European Union (EU). Long-term mental health care for people with severe mental disorders. Available from: https://ec.europa.eu/health/ sites/health/files/mental_health/docs/healthcare_mental_disorders_en. pdf. Accessed April 16, 2021.

55. Biering P. Helpful approaches to older people experiencing mental health problems: a critical review of models of mental health care. Eur J Ageing. 2019;16(2):215-225. doi:10.1007/s10433-018-0490-3

56. Markota M, Rummans TA, Bostwick JM, Lapid MI. Benzodiazepine use in older adults: dangers, management, and alternative therapies. Mayo Clin Proc. 2016;91(11):1632-1639. doi:10.1016/j. mayocp.2016.07.024

57. Cuijpers P, Cristea IA, Karyotaki E, Reijnders M, Huibers MJ. How effective are cognitive behavior therapies for major depression and anxiety disorders? A meta-analytic update of the evidence. World Psychiatry. 2016;15(3):245-258. doi:10.1002/wps.20346

58. Kirkham JG, Choi N, Seitz DP. Meta-analysis of problem solving therapy for the treatment of major depressive disorder in older adults. Int J Geriatr Psychiatry. 2016;31(5):526-535. doi:10.1002/gps.4358

59. Orgeta V, Qazi A, Spector A, Orrell M. Psychological treatments for depression and anxiety in dementia and mild cognitive impairment: systematic review and meta-analysis. Br J Psychiatry. 2015;207 (4):293-298. doi:10.1192/bjp.bp.114.148130

60. Liang JH, Xu Y, Lin L, Jia RX, Zhang HB, Hang L. Comparison of multiple interventions for older adults with Alzheimer disease or mild cognitive impairment: a PRISMA-compliant network meta-analysis. Medicine. 2018;97(20):e10744. doi:10.1097/md.0000000000010744

61. Brodaty H, Arasaratnam C. Meta-analysis of nonpharmacological interventions for neuropsychiatric symptoms of dementia. $\mathrm{Am}$ J Psychiatry. 2012;169(9):946-953. doi:10.1176/appi. ajp.2012.11101529

62. Schnabel K, Binting S, Witt CM, Teut M. Use of complementary and alternative medicine by older adults--a cross-sectional survey. $B M C$ Geriatr. 2014;14:38. doi:10.1186/1471-2318-14-38

63. Siddiqui MJ, Min CS, Verma RK, Jamshed SQ. Role of complementary and alternative medicine in geriatric care: a mini review. Pharmacogn Rev. 2014;8(16):81-87. doi:10.4103/0973-7847.134230

64. Whitlatch CJ, Orsulic-Jeras S. Meeting the informational, educational, and psychosocial support needs of persons living with dementia and their family caregivers. Gerontologist. 2018;58(suppl_1):S58s73. doi:10.1093/geront/gnx162

65. Frost R, Kharicha K, Jovicic A, et al. Identifying acceptable components for home-based health promotion services for older people with mild frailty: a qualitative study. Health Soc Care Community. 2018;26(3):393-403. doi:10.1111/hsc. 12526

66. Elliott RA, Goeman D, Beanland C, Koch S. Ability of older people with dementia or cognitive impairment to manage medicine regimens: a narrative review. Curr Clin Pharmacol. 2015;10 (3):213-221. doi:10.2174/1574884710666150812141525

67. Campbell NL, Boustani MA, Skopelja EN, Gao S, Unverzagt FW, Murray MD. Medication adherence in older adults with cognitive impairment: a systematic evidence-based review. Am $J$ Geriatr Pharmacother. 2012;10(3):165-177. doi:10.1016/j. amjopharm.2012.04.004

68. Brown KW, Coogle CL, Wegelin J. A pilot randomized controlled trial of mindfulness-based stress reduction for caregivers of family members with dementia. Aging \& Mental Health. 2016;20 (11):1157-1166. doi:10.1080/13607863.2015.1065790
69. Kasper JD, Freedman VA, Spillman BC, Wolff JL. The disproportionate impact of dementia on family and unpaid caregiving to older adults. Health Aff. 2015;34(10):1642-1649. doi:10.1377/ hlthaff.2015.0536

70. Martín JM, Olano-Lizarraga M, Saracíbar-Razquin M. The experience of family caregivers caring for a terminal patient at home: a research review. Int $J$ Nurs Stud. 2016;64:1-12. doi:10.1016/j. ijnurstu.2016.09.010

71. Krutter S, Schaffler-Schaden D, Essl-Maurer R, et al. Comparing perspectives of family caregivers and healthcare professionals regarding caregiver burden in dementia care: results of a mixed methods study in a rural setting. Age Ageing. 2019;49(2):199-207. doi:10.1093/ageing/afz165

72. Schmotz C, Richinger C, Lorenzl S. High burden and depression among late-stage idiopathic Parkinson disease and progressive supranuclear palsy caregivers. J Geriatr Psychiatry Neurol. 2017;30 (5):267-272. doi:10.1177/0891988717720300

73. Soontorn T, Pongtriang P, Songwathana P. Thai family caregivers' experiences helping dependent elders during medical emergencies: a qualitative study. Australas Emerg Care. 2020;23(2):71-76. doi:10.1016/j.auec.2019.11.002

74. Lau DT, Kasper JD, Hauser JM, et al. Family caregiver skills in medication management for hospice patients: a qualitative study to define a construct. J Gerontol B Psychol Sci Soc Sci. 2009;64 (6):799-807. doi:10.1093/geronb/gbp033

75. Pretorius RW, Gataric G, Swedlund SK, Miller JR. Reducing the risk of adverse drug events in older adults. Am Fam Physician. 2013;87 (5):331-336.

76. Schulz R, Czaja SJ. Family caregiving: a vision for the future. $\mathrm{Am}$ $J$ Geriatr Psychiatry. 2018;26(3):358-363. doi:10.1016/j. jagp.2017.06.023

77. Trivedi DP, Braun A, Dickinson A, et al. Managing behavioural and psychological symptoms in community dwelling older people with dementia: 1. A systematic review of the effectiveness of interventions. Dementia. 2019;18(7-8):2925-2949. doi:10.1177/ 1471301218762851

78. Zuidema SU, Johansson A, Selbaek G, et al. A consensus guideline for antipsychotic drug use for dementia in care homes. Bridging the gap between scientific evidence and clinical practice. Int Psychogeriatr. 2015;27(11):1849-1859. doi:10.1017/s1041610215000745

79. Ris I, Schnepp W, Mahrer Imhof R. An integrative review on family caregivers' involvement in care of home-dwelling elderly. Health Soc Care Community. 2019;27(3):e95-e111. doi:10.1111/hsc.12663

80. Wolff JL, Spillman BC, Freedman VA, Kasper JD. A national profile of family and unpaid caregivers who assist older adults with health care activities. JAMA Intern Med. 2016;176(3):372-379. doi:10.1001/jamainternmed.2015.7664

81. Roßmeier C, Hartmann J, Riedl L, et al. How do persons with young and late onset dementia die? J Alzheimers Dis. 2021;81(2):843-852. doi:10.3233/jad-210046

82. Ong HL, Vaingankar JA, Abdin E, et al. Resilience and burden in caregivers of older adults: moderating and mediating effects of perceived social support. BMC Psychiatry. 2018;18(1):27. doi:10.1186/ s12888-018-1616-Z

83. Pratt SI, Mueser KT, Driscoll M, Wolfe R, Bartels SJ. Medication nonadherence in older people with serious mental illness: prevalence and correlates. Psychiatr Rehabil J. 2006;29(4):299-310. doi:10.2975/29.2006.299.310

84. Thiyagarajan JA, Araujo de Carvalho I, Peña-Rosas JP. Redesigning care for older people to preserve physical and mental capacity: WHO guidelines on community-level interventions in integrated care. PLoS Med. 2019;16(10):e1002948. doi:10.1371/journal.pmed.1002948

85. Wilson E, Caswell G, Turner N, Pollock K. Managing medicines for patients dying at home: a review of family caregivers' experiences. $J$ Pain Symptom Manage. 2018;56(6):962-974. doi:10.1016/j. jpainsymman.2018.08.019 
86. Pellegrin KL, Krenk L, Oakes SJ, et al. Reductions in medication-related hospitalizations in older adults with medication management by hospital and community pharmacists: a quasi-experimental study. $J$ Am Geriatr Soc. 2017;65(1):212-219. doi:10.1111/jgs.14518

87. Meid AD, Lampert A, Burnett A, Seidling HM, Haefeli WE. The impact of pharmaceutical care interventions for medication underuse in older people: a systematic review and meta-analysis. $\mathrm{Br} \mathrm{J} \mathrm{Clin}$ Pharmacol. 2015;80(4):768-776. doi:10.1111/bcp.12657

88. Gallagher P, Ryan C, Byrne S, Kennedy J, O’Mahony D. STOPP (Screening Tool of Older Person's Prescriptions) and START (Screening Tool to Alert doctors to Right Treatment). Consensus validation. Int $J$ Clin Pharmacol Ther. 2008;46(2):72-83. doi: $10.5414 / \mathrm{cpp} 46072$

89. Gaubert-Dahan ML, Sebouai A, Tourid W, Fauvelle F, Aikpa R, Bonnet-Zamponi D. The impact of medication review with version 2 STOPP (Screening Tool of Older Person's Prescriptions) and START (Screening Tool to Alert doctors to Right Treatment) criteria in a French nursing home: a 3-month follow-up study. Ther Adv Drug Saf. 2019;10:2042098619855535. doi:10.1177/2042098619855535

90. Hill-Taylor B, Walsh KA, Stewart S, Hayden J, Byrne S, Sketris IS. Effectiveness of the STOPP/START (Screening Tool of Older Persons' potentially inappropriate Prescriptions/Screening Tool to Alert doctors to the Right Treatment) criteria: systematic review and meta-analysis of randomized controlled studies. J Clin Pharm Ther. 2016;41(2):158-169. doi:10.1111/jcpt.12372

91. Patterson SM, Cadogan CA, Kerse N, et al. Interventions to improve the appropriate use of polypharmacy for older people. Cochrane Database Syst Rev. 2014;1(10):Cd008165. doi:10.1002/14651858. CD008165.pub3
92. Lewis T. Using the NO TEARS tool for medication review. BMJ. 2004;329(7463):434. doi:10.1136/bmj.329.7463.434

93. Austrom MG, Geros KN, Hemmerlein K, et al. Use of a multiparty web based videoconference support group for family caregivers: innovative practice. Dementia. 2015;14(5):682-690. doi:10.1177/ 1471301214544338

94. Husebø AM, Storm M. Virtual visits in home health care for older adults. ScientificWorldJournal. 2014;2014:689873. doi:10.1155/2014/ 689873

95. Williams KN, Perkhounkova Y, Shaw CA, Hein M, Vidoni ED, Coleman CK. Supporting family caregivers with technology for dementia home care: a randomized controlled trial. Innov Aging. 2019;3(3):igz037. doi:10.1093/geroni/igz037

96. Chi NC, Demiris G. A systematic review of telehealth tools and interventions to support family caregivers. J Telemed Telecare. 2015;21(1):37-44. doi:10.1177/1357633x14562734

97. De Cola MC, Lo Buono V, Mento A, et al. Unmet needs for family caregivers of elderly people with dementia living in Italy: what do we know so far and what should we do next? Inquiry. 2017;54:46958017713708. doi:10.1177/0046958017713708

98. den Herder-van der Eerden M, Hasselaar J, Payne S, et al. How continuity of care is experienced within the context of integrated palliative care: a qualitative study with patients and family caregivers in five European countries. Palliat Med. 2017;31(10):946-955. doi:10.1177/0269216317697898

99. Gillespie RJ, Harrison L, Mullan J. Medication management concerns of ethnic minority family caregivers of people living with dementia. Dementia. 2015;14(1):47-62. doi:10.1177/ 1471301213488900
Risk Management and Healthcare Policy

\section{Publish your work in this journal}

Risk Management and Healthcare Policy is an international, peerreviewed, open access journal focusing on all aspects of public health, policy, and preventative measures to promote good health and improve morbidity and mortality in the population. The journal welcomes submitted papers covering original research, basic science, clinical \& epidemiological studies, reviews and evaluations, guidelines, expert opinion and commentary, case reports and extended reports. The manuscript management system is completely online and includes a very quick and fair peer-review system, which is all easy to use. Visit http://www.dovepress.com/testimonials.php to read real quotes from published authors. 